\title{
Design adaptation of the automobile and tractor diesel engine for work on mixed vegetable-mineral fuel
}

\author{
Alexei Khokhlov ${ }^{1}$, Anton Khokhlov ${ }^{1}$, Dmitry Maryin ${ }^{1}$, Denis Molochnikov ${ }^{1, *}$, and Ilnar Gayaziev ${ }^{2}$ \\ ${ }^{1}$ Ulyanovsk State Agrarian University named after P.A. Stolypin, 432017 Ulyanovsk, Russia \\ ${ }^{2}$ Kazan State Agrarian University, 420015 Kazan, Republic of Tatarstan, Russia
}

\begin{abstract}
The article is devoted to the solution of the problem associated with the partial substitution of marketable mineral diesel fuel (DF) with mixed vegetable-mineral (MDF) engine fuel. The bio-component of MDF is vegetable oil, for example, Camelina seed oil. A design option of a dual-fuel feeding system has been proposed, the main component of which is a mixing and metering unit for vegetable oil and mineral diesel fuel which allows electric metering units controlled by an electronic control unit (ECU) to respond to signals from diesel load-speed sensors (crankshaft speed, injector rack position (fuel injection pump)) and temperature gauge of camelina oil, to ensure the feed of mixed diesel fuel with components of different content. The use of mixed diesel fuel based on vegetable oil, containing for example $50 \%$ of mineral commercial fuel and $50 \%$ of camelina oil, makes it possible with a slight decrease in the effective power (not more than $6 \%$ ) and some increase in the specific effective consumption of mixed fuel (up to $14 \%$ ) to save $50 \%$ of fuel of petroleum origin, as well as to reduce the smoke opacity of exhaust gases by 17-20\% and reduce the content of carbon oxide by 35-40\% compared with the work of a diesel engine on commercial mineral diesel fuel.
\end{abstract}

\section{Introduction}

The energy efficiency improvement of the world economy and development of renewable energy sources is one of the main objectives of the present time. A promising direction to solve this problem is the partial substitution of diesel fuel with mixed vegetable-mineral fuel [1]. Rapeseed oil has become the most common in the Russian Federation and the EU as a biological component of MDF, which is widely used in the food industry. The cultivation of rapeseed requires fertile land, warm temperatures, moisture and careful adherence to the technology of cultivation. All this confines the cultivation of rape seed only to countries with favorable climatic conditions [2, 3]. Therefore, one of the promising biocomponents of MDF is camelina oil (camoil), which is obtained from the seeds of camelina. Camelina seeds can be cultivated both as an annual, and a winter crop. Camelina belongs to frost and drought resistant crops, with low requirements for sunshine, moisture and fertilizers and can be cultivated in various climatic zones [4-6].

\section{Materials and methods}

Operational studies were conducted on the farm "Vozrozhdenie" (Revival) of the Ulyanovsk region. Two tractors of the MTZ-82 model were used in the study. One tractor was used as a control one - it ran on commercial mineral diesel fuel (100\% diesel fuel), another experimental one - ran on mixed camelina oilmineral fuel $50 \%$ camelina oil $+50 \%$ diesel fuel (this composition of mixed diesel fuel was selected on the basis of tribological studies of mixed camelina oilmineral fuel and accelerated testing of pump units of the fuel injection pump for wear of plunger pairs).

The tractors of the same year of manufacturing were under observation, with approximately the same operating time and carrying out the same amount of work at the cattle-breeding farm of an enterprise.

The following items were taken as the assessment indicators of plunger pair wear rates in pump units of the fuel injection pump: geometric dimensions of parts of plunger pairs (ovality and taper of the plunger, diameters of the plunger and sleeve, annular gap between the plunger and sleeve); the weight of parts of plunger pairs (plunger, bushing); volumetric cyclic fuel feeding, hydraulic density of plunger pairs.

Prior to operation studies for the fuel injection pumps, new plunger pairs U16c15 (4UTNM 111141001) from one manufactured batch of the Altai fuel equipment plant were selected for the injection pumps to be installed on the tractors under study. Before installation, the parts of each plunger pair were marked, weighed, and their original geometrical dimensions were measured, and plunger pairs were tested for hydraulic density.

Each fuel injection pump with control plunger pairs was adjusted on the bench for adjusting and testing highpressure fuel pumps in accordance with the running parameters of the diesel engine D-243 (4Ch 11 / 12,5). A

* Corresponding author: denmol@yandex.ru 
dual-fuel system for running on a mixed camelina oilmineral fuel was installed on the experimental tractor.

Monitoring the operation of the tractors under study was carried out on the basis of operation time $T_{\text {tr }}$, running hours (according to the standard counters of running hours), and the fuel consumed $\mathrm{G}_{\text {sum }}, \mathrm{kg}$ (according to registration-intake fuel consumption cards).

\section{The results of the study}

A dual-fuel feeding system for diesel engines was developed and manufactured for the design adaptation of an automobile and tractor diesel engine to work on two types of fuel RF patent for invention No. 2582535 [7, 8]. The proposed dual-fuel feeding system ensures the preparation of MDF, depending on the load-speed mode of a diesel engine, directly during tractor operation (Fig. 1).

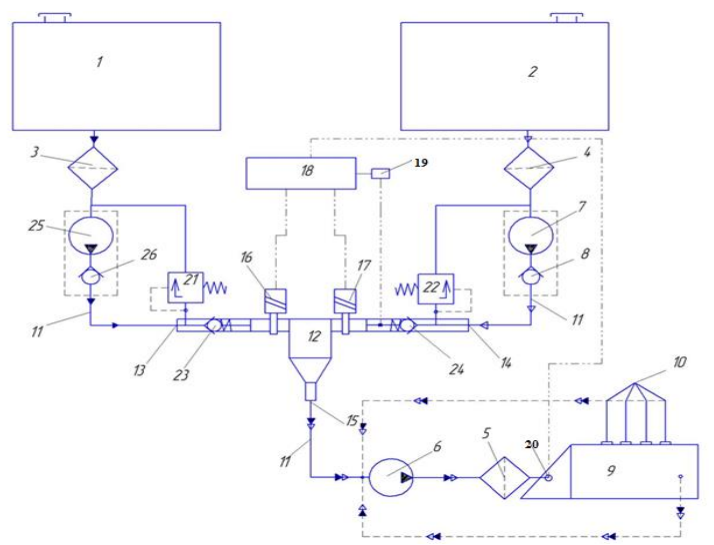

Fig. 1. The scheme of the dual fuel feeding system of a diesel engine (name of positions in the text).

According to the patent obtained: "The dual-fuel feeding system contains (Fig. 1) a tank of mineral fuel 1, a tank of vegetable oil 2, coarse filters for mineral fuel 3 and vegetable oil 4 , a filter for fine cleaning of fuel 5, a primary fuel pump 6 , an electric pump for feeding vegetable oil 7 with a check valve 8 , a high-pressure fuel pump complete with the centrifugal speed governor 9, nozzles 10 , fuel lines 11 and a vegetable oil and mineral diesel fuel metering unit 12, having two inlet ducts 13 , 14 and one outlet 15 .

In the inlet ducts 13,14 electric metering units 16,17 are installed, electrically connected through an electronic control unit 18 with a temperature gauge of vegetable oil 19 and an inductive load-speed mode sensor 20. In the inlet ducts 13, 14 of the metering unit of vegetable oil and mineral diesel fuel 12 ahead of electric metering units 16, 17 bypass 21, 22 and injection valves 23, 24 of mineral fuel and vegetable oil are installed. Between the coarse mineral fuel filter 3 and mineral fuel injection valve 23 an electric pump of mineral fuel feed 25 is placed with a check valve 26 ."

Starting, warming up and stopping the diesel engine are carried out on mineral fuel. At the same time, the mineral fuel electric metering unit 16 is fully open, and the electric metering unit of vegetable oil 17 is completely closed. Mineral fuel from the mineral fuel tank 1 , passing the coarse mineral fuel filter 3 , enters a running electric pump for feeding mineral fuel 25 , which is by the created fuel pressure exceeding the response pressure of the mineral fuel injection valve 23 , opens it and feeds mineral fuel through the electric metering unit 16 , the mixing - metering unit of vegetable oil and mineral diesel fuel 12 , the primary fuel pump 6 , the fine fuel filter 5, the fuel injection pump 9. And further by injection nozzles 10 it is injected into diesel cylinders. The pressure of the fuel created by the electric pump 25 is maintained by the adjustable mineral fuel bypass valve 21 .

After warming up the diesel on mineral fuel, the electric pump for feeding vegetable oil 7 is turned on, which is by the created oil pressure exceeding the response pressure of the vegetable oil injection valve 24 , opens it and feeds the oil through the electric metering unit 17 to the mixing metering unit of vegetable oil and mineral diesel fuel 12 .

Oil pressure created by the electric pump 7 is maintained by the adjustable bypass valve of vegetable oil 22. Mineral fuel is fed into the mixing - metering unit of vegetable oil and mineral oil diesel fuel 12 and the process is similar to the start and warm-up mode of a diesel engine. In the mixing and metering unit of vegetable oil and mineral diesel fuel 12 mineral fuel and vegetable oil are mixed, forming mixed diesel fuel, which is discharged through the outlet duct 15 .

Depending on the informative signals received from the temperature gauge of vegetable oil 19 and the sensor of the load-speed mode 20, and sent through the electronic control unit 18 into the electrical circuit of the electric metering units 16,17 . The electric metering unit of vegetable oil 17 is opened to the appropriate size, and the electric metering unit of mineral fuel 16 is closed to the same size changing the percentage ratio of mineral fuel and vegetable oil in the mixed fuel.

The bypass valves 21,22 , due to the discharge of a part of the mineral fuel and vegetable oil in the suction cavity of the electric pumps 25,7 , maintain a constant pressure in the inlet ducts 13,14 of the vegetable oil and mineral diesel fuel metering unit 12 ahead of the electric metering units. This increases the accuracy of the percentage of mineral and vegetable components in the mixed fuel, regardless of the difference in their properties.

When one of the electric pumps 25,7 stops working, the injection valves 23,24 exclude the rapid pressure drop of the fuel and oil ahead of the electric metering units 16,17 . In addition, with low consumption of mixed fuel and different levels of mineral fuel and vegetable oil in their tanks, the injection valves 23,24 , along with maintaining a constant pressure in the inlet ducts 13,14 of the mixing and metering unit of vegetable oil and mineral diesel fuel 12, with open electric metering units 16,17 , prevent one type of component from flowing into the other tank.

The check valves 8,26 are standard units of electric pumps 7 and 25 and are designed to prevent the drainage of vegetable oil and mineral fuel and the formation of air pockets when electric pumps 7 and 25 are turned off. Before stopping the engine in response to a signal from the ECU, the electric metering unit of mineral fuel 16 
opens fully and the electric metering unit of vegetable oil 17 is fully closed. After burning up mixed fuel from the mixing unit and filling it with mineral diesel fuel, the engine stops. To ensure high-quality mixing and the required percentage of components of MDF when a diesel engine is running on mixed camelina oil-mineral fuel, a patented design of a vegetable oil and mineral diesel fuel metering unit is proposed (RF patent for invention No. $2582700[8,9])$.

According to the patent, the mixing and metering unit contains (fig. 2) a cover 1, plugs 2, an electric diesel fuel meter 3, an electric metering unit of vegetable oil 4 , a special bolt 5 , a pipe union 6 , a damper screen 7 , metal packing 8 , a diesel fuel inlet duct 9 , a vegetable oil inlet duct 10 , working cavity 11 , mixing cavity 12 and outlet duct of mixed diesel fuel 13 .

Components to be mixed (mineral fuel and vegetable oil) through the inlet ducts for components 9 and 10, as well as electric metering units 3 and 4, placed on the cover 1 , go to the working cavity 11 of the mixing unit. From the working cavity 11 through the duct in a special bolt 5 , the components enter the mixing cavity 12 .

The mixed components pass through the labyrinths of metal packing 8 constantly changing speed and direction of motion, due to which they are intensively mixed. The prepared mixed fuel from the cavity 12, after passing through the damper screen 7 , leaves the mixing unit through the outlet duct of the mixed fuel 13 and enters the U-shaped duct of the fuel injection pump and then to the nozzles of an engine".

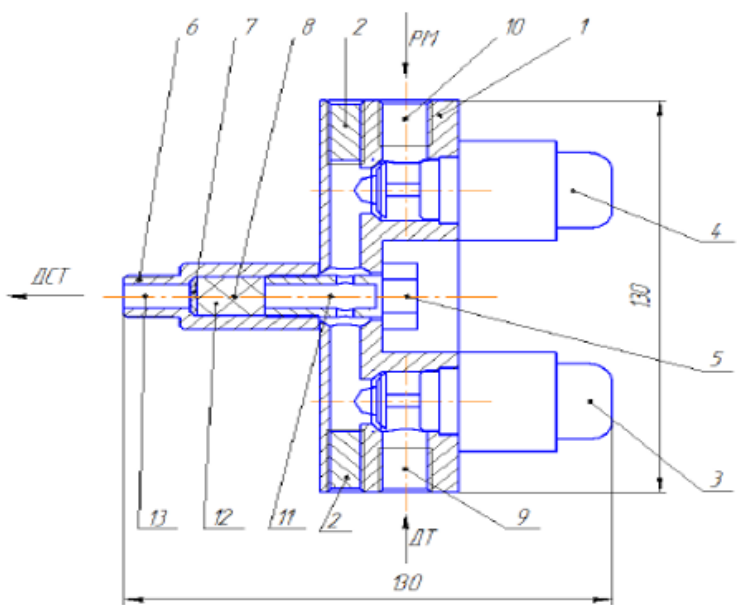

Fig. 2. Scheme of the mixing and metering unit of vegetable oil and mineral diesel fuel: (the name of positions in the text).

The general view of the mixing and metering unit of vegetable oil and mineral diesel fuel is presented in fig. 3 .

The mixing and metering unit of vegetable oil and mineral diesel fuel provides high-quality mixing and exact dispensing of MDF components owing to the application of electric metering units controlled by the electronic control unit (ECU) depending on the loading and high-speed mode of the diesel and temperature of vegetable oil. The small volume of the mixing cavity makes it possible to quickly feed the required composition of MDF when changing the mode of operation of the engine, as well as to reduce the engine operation time before it stops.

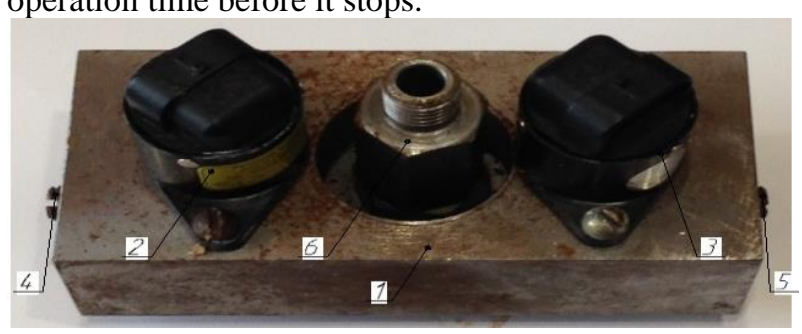

Fig. 3. General view of the mixing and metering unit of vegetable oil and mineral diesel fuel: 1 - mixer; 2,3 - electric diesel fuel and vegetable oil metering units; 4,5 - inlet ducts of mineral diesel fuel and vegetable oil; 6 - outlet duct of mixed fuel.

The STM 32 microcontroller was taken as the basis when developing the ECU. A program for the ECU microcontroller has been developed, which provides the feed of mixed diesel fuel in accordance with the operation mode of a diesel engine [10,11]. On the basis of the developed block diagrams, an ECU program of work was made to ensure the operation of electric metering devices that set the required ratio of MDF components depending on the diesel load-speed mode and the temperature of vegetable oil determined by the temperature gauge, which is a thermocouple (Fig. 5).

The mixing unit was calibrated by means of mixing mineral diesel fuel and vegetable (camelina oil) to produce mixed diesel fuel with a different ratio of components. The composition of mixed camelina oilmineral fuel is set by electric metering units of a mixing unit in response to the ECU signals. The required percentage of camelina oil and mineral diesel fuel in MDF is set by pressing the "fuel composition" buttons of the control of electric metering units (Fig. 4).

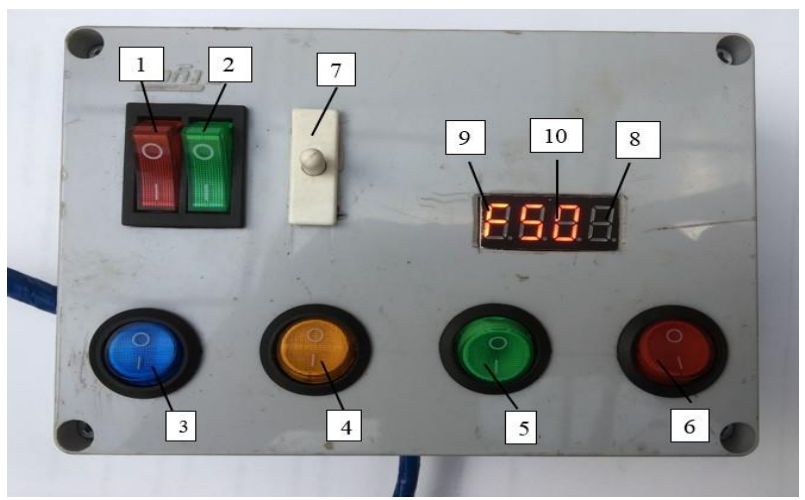

Fig. 4. General view (top view) of the electronic control unit: 1 - on / off button of power supply; 2 - button 0 of mineral fuel feed (DF100\%); 3 - button 1 of the fuel composition (Camoil 10\% + DF90 \%); 4 - button 2 of the fuel composition (Camoil $25 \%+$ DF75 \%); 5 - button 3 of the fuel composition ( Camoil $50 \%+$ DF50 \%); 6 - button 4 of the fuel composition (Camoil $75 \%+$ DF25 \%); 7 - button for fixing the fuel composition; 8 - digital electronic display; 9 - fixation mode; 10 - fuel composition.

Before starting a tractor, the electric power is supplied to the ECU ( 1 - the button of power on / off). The button $2-0$ of the fuel composition is turned on while the mixing and metering units ensure the feed of 
only mineral diesel fuel ( 0 is displayed on the digital electronic display 8). By switching on the corresponding fuel composition buttons $3,4,5,6$, the mixing and electric metering units provide the feeding of MDF with the following percentage ratio of components: $10 \%$ camelina oil $+90 \%$ DF ( 1 - fuel composition, 10 is displayed on the digital electronic display) $25 \%$ camelina oil $+75 \%$ DF ( 2 - fuel composition, 25 is displayed on the digital electronic display), $50 \%$ camelina oil $+50 \%$ DF ( 3 - fuel composition, 50 is displayed on the digital electronic display) and $75 \%$ camelina oil $+25 \%$ DF (4 - fuel composition 75 is displayed on the digital electronic display).Each fuel composition type, except for zero, has an automatic adjustment of the MDF feed (within the specified fuel composition) by the signals of the diesel load-speed mode sensor (Fig. 5), consisting of an end position sensor for the injector rack and a magnetic induction sensor of the engine crankshaft speed.

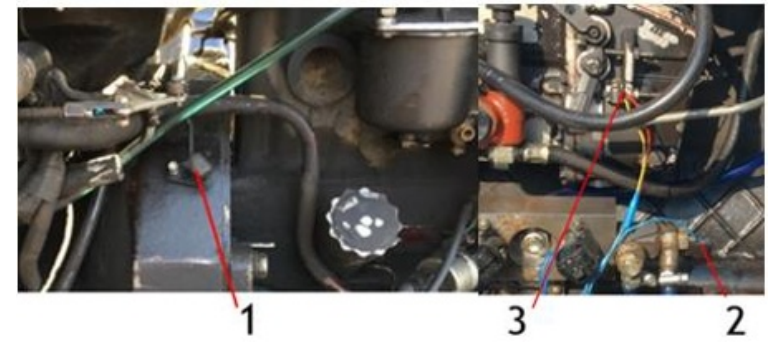

Fig. 5. Sensor installation locations: 1 - crankshaft speed sensor; 2 - temperature gauge; 3 - injector rack position.

There is a button in the ECU for fixing the fuel composition (7), when turned on, the maximum amount of camelina oil corresponding to the included fuel composition is fed (the symbol " $\mathrm{F}-9$ " and the number of the corresponding fuel composition type "10" are displayed on the electronic display in Fig. 4). Operational studies were carried out on the third fuel composition type (50\% of camelina oil and $50 \%$ of DF) with the fuel composition fixation button on.

\section{Conclusion}

The advantages of the developed dual-fuel system and the mixing and metering unit are the versatility of use in various types of automotive diesel engines, multi-fuel, free availability of components and parts, the ability to manufacture in small enterprises, competitiveness, small capital investments and short payback period. The use of diesel fuel based on vegetable oil, containing for example $50 \%$ of mineral commercial fuel and $50 \%$ of camelina oil, makes it possible with a slight decrease in the effective power (not more than $6 \%$ ) and some increase in the specific effective consumption of mixed fuel (up to $14 \%$ ) to save $50 \%$ of fuel of petroleum origin, as well as to reduce the smoke opacity of exhaust gases by $17-20 \%$ and reduce the content of carbon monoxide by $35-40 \%$ compared with the work of a diesel engine on commercial mineral diesel fuel.

\section{References}

1. A.L. Khokhlov, A.A. Guzyaev, A.A. Khokhlov, The necessity to substitute mineral motor fuel for mixed diesel fuel in Mater. of the VII Int. Sci. Conf. "Agrarian science and education at the present stage of development: experience, problems and ways to solve them" 252-258 (Ulyanovsk State Agrarian University named after P.A. Stolypin, Ulyanovsk, 2016)

2. A.P. Ukhanov, D.A. Ukhanov, L.I. Sidorov, The use of radish oil as a biocomponent of mixed diesel fuel (Penza State Agrarian University, Penza, 2018)

3. D.A. Ukhanov, A.P. Ukhanov, Diesel fuel supply when working on rapeseed-mineral fuel (Penza State Agrarian University, Penza, 2018)

4. A.P. Ukhanov, A.A. Khokhlov, A.L. Khokhlov, V.A. Golubev, E.A. Khokhlova, Physical properties of camelina oil-mineral fuel Int. res. J. 05(59), 124128 (LLC POLYGRAPHIST Company, Ekaterenburg, 2017)

5. E.G. Rotanov, A.L. Khokhlov, A.A. Khokhlov, Effect of surfactants of mixed fuel on the wear of a plunger and barrel assembly Rural farm machinery operator 6, 36-37 (2018)

6. A.P. Ukhanov, E.G. Rotanov, A.A. Khokhlov, Theoretical estimation of the life time of plunger and barrel assemblies of the high-pressure fuel pump when working on a mixed camelina oil-mineral fuel Bull. of the Ulyanovsk State Agricult. Acad. 2(42), 18-22 (2018)

7. A.P. Ukhanov, D.A. Ukhanov, A.A. Khokhlov, E.G. Rotanov, A.L. Khokhlov, Diesel fuel supply system, Patent no. 2582535 of the Russian Federation IPC F02M 43/00, F02D 19/06. 2014152644/06; appl. 12/24/2014; publ. 04/27/2016 Bul. no. 12.

8. A.P. Ukhanov, D.A. Ukhanov, E.A. Khokhlova, A.A. Khokhlov, Devices for design adaptation of diesel engines of automobile and tractor equipment to work on biomineral fuel News of the Samara State Agricult. Acad. 2, 34-40 (2016)

9. A.P. Ukhanov, D.A. Ukhanov, A.A. Khokhlov, E.G. Rotanov, A.L. Khokhlov, Mixing and metering unit of vegetable oil and mineral diesel fuel, Patent no. 2582700 of the Russian Federation IPC B01F 5/06. 2014152680/05; appl. 12/24/2014; publ. 04/27/2016 Bul. no. 12.

10. A.P. Ukhanov, E.A. Khokhlova, A.A. Khokhlov, Automatic system for supplying mixed diesel fuel Sci. thought 3, 108-112 (2017)

11. A.P. Ukhanov, A.L. Khokhlov, A.A. Khokhlov, S.A. Dolgov, Development of an automatic system for feeding mixed diesel fuel in Mater. of the VIII Int. Sci. Conf. "Agrarian science and education at the present stage of development: experience, problems and ways to solve them" 273-278 (Ulyanovsk State Agrarian University named after P.A. Stolypin, Ulyanovsk, 2017). 